This peer reviewed manuscript has been accepted for publications to the Lubrication Science. Cite this article as: A. Pogačnik, A. Kupec, M. Kalin, Tribological properties of polyamide (PA6) in self mated contacts and against steel as a stationary and moving body, Wear, Volumes 378-379, 2017, Pages 17-26, ISSN 0043-1648, https://doi.org/10.1016/j.wear.2017.01.118.

\title{
Tribological properties of polyamide (PA6) in self-mated contacts and against steel as a stationary and moving body
}

\author{
A. Pogačnik ${ }^{\mathrm{a}}$, A. Kupec ${ }^{\mathrm{b}}$ and *M. Kalin ${ }^{\mathrm{b}}$ \\ ${ }^{a}$ KISSsoft AG, Bubikon, Switzerland, \\ baboratory for tribology and interface nanotechnology, Faculty of Mechanical Engineering, \\ University of Ljubljana, Bogišičeva 8, 1000 Ljubljana, Slovenia \\ * corresponding author; mitjan.kalin@tint.fs.uni-lj.si
}

\begin{abstract}
The time for which each contacting body is exposed to a tribological contact affects its interface temperature, third-body and tribofilm formation, and, as a result, the overall tribological behaviour, which may be particularly relevant with very dissimilar material pairs. This work focuses on the tribological properties of unreinforced polyamide (PA6) in selfmated contacts or against steel (SS) as a stationary (SS/PA6) or a moving contact (PA6/SS) body under dry-sliding conditions. Moreover, the effects of the contact pressure and the sliding velocity were investigated for these contacts. In addition, the contact conditions were carefully controlled with measurements of the specimen's surface temperature using an infrared camera. The results show that the tribological behaviour indeed depends significantly on the contact configuration. The tribological properties of the stationary steel pin sliding against a rotating polymer disc (SS/PA6), as well as of a self-mated PA6/PA6 contact, depended substantially on the contact conditions used. In contrast, the contact configuration of a stationary PA6 pin sliding against a rotating steel disc (PA6/SS) showed only a negligible effect on changes in the sliding speed and the load. Moreover, this was clearly the bestperforming contact in the study and the beneficial effect is explained by the ability of a rotating disc to remove the heat from the contact zone and, consequently, to lower the temperatures generated in the tribological contact.
\end{abstract}

Keywords: polyamide, PA6, friction, wear, temperature 
This peer reviewed manuscript has been accepted for publications to the Lubrication Science. Cite this article as: A. Pogačnik, A. Kupec, M. Kalin, Tribological properties of polyamide (PA6) in self mated contacts and against steel as a stationary and moving body, Wear, Volumes 378-379, 2017, Pages 17-26, ISSN 0043-1648, https://doi.org/10.1016/j.wear.2017.01.118.

\section{Introduction}

The use of plastic materials in tribological applications has grown rapidly in the past decade, mainly due to some advantages that plastic materials have over typical tribology materials, i.e., metals. The main advantages are their low weight, low price for high-volume production, reduced noise level, chemical inertness and good tribological properties without lubrication [1]. These reasons make polymers suitable substitutes for conventional materials in many tribological contacts $[2,3]$.

However, plastic materials also have some disadvantages compared to metals, like inferior mechanical properties, less thermal conductivity and lower operating temperatures, which need to be taken into account. In contrast to other materials, the tribological properties of polymers depend on the tensile strength and the toughness rather than on the hardness $[2,3]$. Due to their thermal properties, polymers are very sensitive to frictional heating; therefore, during the tribological testing, besides the load and velocity, the temperature in the contact needs to be considered as well. The latter is difficult to predict theoretically, due to a strong dependency on the real contact area, which is very hard to estimate reliably, especially with polymers, where the material's mechanical properties and deformation go thorough significant modifications within the contacts. Accordingly, some kind of contact-temperature measurements seem to be more pragmatic and, besides mathematical models, various approaches have been used in the past. For example, an infrared camera [4,5], sometimes in combination with thermocouples [5], was used for an evaluation of the average surface temperatures during a pin-on-disc experiment with metallic contacts [5] and during the meshing of PA6 gears [4]. A comparison of the measured temperatures with mathematical models revealed that, depending on the model used, the predicted temperatures can deviate greatly from the actual temperatures evolved in a contact [5].

Furthermore, all-plastic contacts, rather than plastic/metal, are generally more favourable for industrial applications due to reduced costs and weight. However, due to the low thermal conductivity of both the bodies in the contact, these contacts have a lower performance 
This peer reviewed manuscript has been accepted for publications to the Lubrication Science. Cite this article as: A. Pogačnik, A. Kupec, M. Kalin, Tribological properties of polyamide (PA6) in self mated contacts and against steel as a stationary and moving body, Wear, Volumes 378-379, 2017, Pages 17-26, ISSN 0043-1648, https://doi.org/10.1016/j.wear.2017.01.118.

capability compared to steel/plastic contacts, which can more effectively reduce the heat through the steel body [6-9]. In other words, a relatively small increase in temperature can make a significant and step-change deterioration of the mechanical and tribological properties when these values are close to the limit values. Accordingly, in order to appropriately design an all-plastic tribological contact, we have to know precisely the dependence of the mechanical properties on the temperature for the used materials, and how different contact conditions affect these properties.

Some of the most frequently used plastic materials for tribological applications are the polyamides (typically denoted as PA), due to their good wear resistance, high strength and toughness combined with a good impact resistance and low cost [1, 10]. The main disadvantage of polyamides is their high sensitivity to humidity, which influences their mechanical properties and dimensional stability, and poor thermal properties, including a low heat conductivity, large thermal expansion and low temperature limits $[1,10]$. Nevertheless, they are attractive candidates for applications such as bearings and gears, if properly designed.

There have been numerous studies regarding the tribological properties of PA plastics against steel [9, 11-17]. Mainly, the influences of speed and load on the tribological properties have been investigated. The coefficient of friction for PA/steel contacts is reported to be generally in range of $0.3-0.5$, typically below $0.8[9,11-14,16,17]$, but some extreme values of 2.0 were also observed [6]. In addition, a discrepancy in the friction behaviour and the mechanisms was reported: sometimes the coefficient of friction increased with increasing load $[9,13,14]$, but sometimes it decreased with increasing load [18]. Such an inconsistency could be connected to the observed load affecting the coefficient of friction when exceeding the limits due to polymer melting $[1,8]$.

Some authors have also studied the tribological properties of PA against a plastic counter body, such as polyamides, polyesters and polystyrenes [7, 9, 19-22]. However, due to the variety of different plastics used in these tests, any comparison of the results is very difficult and inconsistent. The coefficient of friction for $\mathrm{PA} /$ plastic contacts covers a wide range between 0.1 and 0.9, but typically decreases with an increasing load [7, 19-21]. Furthermore, reinforced polymers and nanocomposites promise an even wider range of applications $[14,16$, $17,23]$, but with even more variation in the tribological performance. 
This peer reviewed manuscript has been accepted for publications to the Lubrication Science. Cite this article as: A. Pogačnik, A. Kupec, M. Kalin, Tribological properties of polyamide (PA6) in self mated contacts and against steel as a stationary and moving body, Wear, Volumes 378-379, 2017, Pages 17-26, ISSN 0043-1648, https://doi.org/10.1016/j.wear.2017.01.118.

In addition to the typically investigated and discussed contact conditions via pressure and velocity variations, there is another important phenomenon affecting the tribological behaviour of polymers that lacks attention in the literature. Namely, the two contact bodies are not equally exposed in the tribological contact, i.e., while one surface is in contact all the time, the counter surface has time to cool down before re-entering the contact. As an example, one can think of a tribological contact of meshing gears with different numbers of teeth, bearings, sliding guides, etc., where the tribological exposure times vary a lot. Similarly, this is the case in all the model-based tribology studies, where the stationary pin is exposed to the tribological contact much more than the rotating disc.

This study focuses on investigating the above-mentioned effect. Unreinforced PA6 was selected, instead of composites, in order to eliminate the effects of fillers and understand the basic material's response to different tribological conditions, in various contact configurations: PA6/PA6, steel/PA6 and PA6/steel. A huge influence of the material pair's configuration in the tribological contact was found and is reported here. The load- and velocity-dependent coefficient of friction, the wear rate and the wear mechanisms are discussed and related to the experimentally measured temperatures evolved in the vicinity of a tribological contact.

\section{Experimental details}

\subsection{Materials used}

Unreinforced polyamide 6 (PA6, Ultramid ${ }^{\circledR}$ B3S, BASF, Germany) and stainless steel (SS, $\mathrm{X} 105 \mathrm{CrMo17})$ were used to prepare cylindrical specimens with the dimensions $\Phi 3 \mathrm{~mm} \times 14 \mathrm{~mm}$ (PA6 and SS), further denoted as the pin, and with the dimensions $\Phi 50 \mathrm{~mm} \times 17 \mathrm{~mm}$ (in case of PA6) or $\Phi 50 \mathrm{~mm} \times 8 \mathrm{~mm}$ (in case of SS), further denoted as the discs.

PA6 material in granular form was injection moulded (BOY 35, UK) to the desired specimen shape, i.e., discs or pins. Due to the uneven shrinkage of the polymer material, the discs were additionally machined to achieve the desired parallel surfaces.

The stainless-steel specimens were cut from a steel rod and machined to produce the desired geometry. Subsequently, the SS samples were quenched and the achieved surface hardness of 
This peer reviewed manuscript has been accepted for publications to the Lubrication Science. Cite this article as: A. Pogačnik, A. Kupec, M. Kalin, Tribological properties of polyamide (PA6) in self mated contacts and against steel as a stationary and moving body, Wear, Volumes 378-379, 2017, Pages 17-26, ISSN 0043-1648, https://doi.org/10.1016/j.wear.2017.01.118.

$735 \mathrm{HV}_{0.1}$ (which corresponds to $\sim 58 \mathrm{HRC}$ ) was measured with a microhardness tester (Leitz Miniload, Wild Leitz GmbH, Germany).

Prior to the testing, the surfaces of disc specimens were finished (RotoPol-21, Struers, Denmark) to the desired roughness of $S_{a}=0.30 \mu \mathrm{m} \pm 0.05 \mu \mathrm{m}$, as measured with a 3D optical interferometer (Contour GT-K0, Bruker, Arizona, USA) and cleaned with high purity ethanol. The basic properties of the materials used are collected in Table 1. Despite the fact that the hardness values of PA6 and SS cannot be directly compared, they are given in the table for completeness. Ultramid ${ }^{\circledR}$ B3S exhibits a tensile strength and a charpy notched impact strength of $45 \mathrm{MPa}$ and $50 \mathrm{~kJ} / \mathrm{m}^{2}$, respectively [24].

Table 1: Basic properties of the materials used.

\begin{tabular}{|l|l|l|}
\cline { 2 - 3 } \multicolumn{1}{l|}{} & PA6 & SS \\
\hline Density, $\mathrm{g} / \mathrm{cm}^{3}$ & 1.13 & 7.65 \\
\hline $\begin{array}{l}\text { Glass-transition temperature, } \\
{ }^{\circ} \mathrm{C}\end{array}$ & 60 & 1500 \\
\hline Thermal conductivity, W/mK & 0.33 & 24.2 \\
\hline Specific heat, J/kgK & 1700 & 460 \\
\hline Hardness & $170 \mathrm{MPa}^{*}$ & $58 \mathrm{HRC}$ \\
\hline
\end{tabular}

"Ball indentation hardness according to ISO 2039-1, scale H 358/30.

\subsection{Tribological tests}

Dry-sliding wear tests were performed using a pin-on-disc configuration, as schematically shown in Figure 1a, using a tribological tester (CSM Instruments, Peseux, Switzerland). The machine consists of a turntable, which holds a rotating disc, and an upper pivoting arm, which holds a stationary pin. The coefficient of friction with the sliding distance and time is measured via the deflection of the pivoting arm. Additional information about the operation of the pin-on-disc machine can be found elsewhere [25]. During the tribological tests, the pin temperature was measured using a thermal camera (Flir A320, Flir, USA), Figure 1b. The temperature measurements were conducted on the exit side of the contact, just above the 
This peer reviewed manuscript has been accepted for publications to the Lubrication Science. Cite this article as: A. Pogačnik, A. Kupec, M. Kalin, Tribological properties of polyamide (PA6) in self mated contacts and against steel as a stationary and moving body, Wear, Volumes 378-379, 2017, Pages 17-26, ISSN 0043-1648, https://doi.org/10.1016/j.wear.2017.01.118.

pin/disc contact line, with a special close-up 50- $\mu$ m lens (Flir, USA). The emissivity of the PA6 material, equal to 0.92, was taken into account for the maesurement. The SS pins were covered with a material of known emissivity (0.97).

The influences of different geometrical configurations, contact pressures (0.55-1.10 MPa) and velocities $(0.4-1 \mathrm{~m} / \mathrm{s})$ on the tribological behaviour were investigated, as collected in Table 2 . Three different contact configurations were studied, i.e., PA6 pin sliding against steel disc (PA6/SS), SS pin sliding against PA6 disc (SS/PA6) and PA6 in self-mated contact (PA6/PA6). The test lengths of $25 \mathrm{~km}$, for the combinations of steel and polymer, or $50 \mathrm{~km}$, for the polymer in the self-mated contact, were selected in order to reach a fully steady-state sliding condition [25]. This can have a significant effect on the reported data if it is not the case.

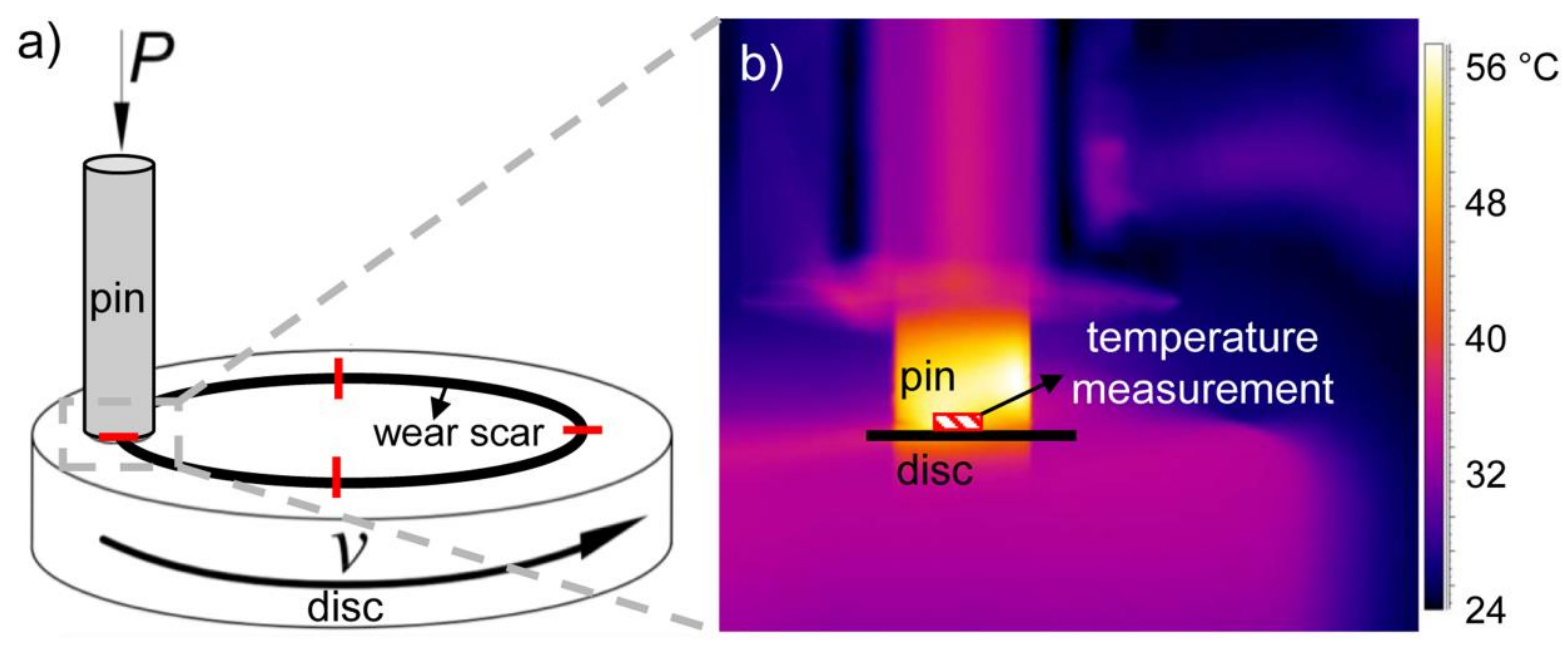

Figure 1: a) Schematic of the pin-on-disc configuration, the red lines on the wear scar denote four points that were taken into account for the disc's wear-rate analysis. b) a typical thermographic picture of the set up during the measurement.

Table 2: Summary of the testing conditions.

\begin{tabular}{|c|c|c|c|c|}
\hline Pin & Disc & $\begin{array}{l}\text { Sliding } \\
\text { speed, } \\
\mathrm{m} / \mathrm{s}\end{array}$ & $\begin{array}{l}\text { Load } \\
N \\
(M P a)\end{array}$ & $\begin{array}{l}\text { Test } \\
\text { length, } \\
\mathrm{km}\end{array}$ \\
\hline PA6 & SS & 0.4 & $4(0.55)$ & 25 \\
\hline
\end{tabular}


This peer reviewed manuscript has been accepted for publications to the Lubrication Science. Cite this article as: A. Pogačnik, A. Kupec, M. Kalin, Tribological properties of polyamide (PA6) in self mated contacts and against steel as a stationary and moving body, Wear, Volumes 378-379, 2017, Pages 17-26, ISSN 0043-1648, https://doi.org/10.1016/j.wear.2017.01.118.

\begin{tabular}{|c|c|c|c|c|}
\hline & & 0.7 & $6(0.85)$ & \\
\hline \multirow{3}{*}{ SS } & & 1 & $8(1.10)$ & \\
& & 0.4 & $4(0.55)$ & \\
& & 0.7 & $6(0.85)$ & 25 \\
\hline \multirow{2}{*}{ PA6 } & \multirow{2}{*}{ PA6 } & 0.7 & $8(1.10)$ & \\
& & 1 & $8(0.55)$ & \\
& & $0.45)$ & 50 \\
\hline
\end{tabular}

All the measurements were performed at a constant radius of $18 \mathrm{~mm}$ to prevent its possible effect on the wear [26]. Each test was repeated at least two times in order to minimize data scattering and the averaged values of the repeated test results are presented. The measurements were made at an atmospheric temperature of $24 \pm 2{ }^{\circ} \mathrm{C}$ and a relative humidity of $40 \pm 10 \%$. In order to ensure the appropriate experimental contact conditions, special attention was paid to the alignment of the pin surface and the counterface. In the pre-testing flattening procedure, the upper specimen (pin) slid against various abrasive papers, i.e., 300, 800 and 1200, for a length of $1 \mathrm{~m}$ under a load of $5 \mathrm{~N}$ and a speed of $0.1 \mathrm{~m} / \mathrm{s}$. After the discs were mounted into the turntable, its height differences over the surface were controlled and did not exceed $0.015 \mathrm{~mm}$.

The pin wear rates were determined based on the loss of weight and the reduction in length. An analytical balance (XA 210/X, Radwag, Poland) with a 0.01-mg readability and a micrometre screw with a readability of $0.005 \mathrm{~mm}$ were used. The weight and length prior to and after the tribological tests were measured five times and the averages of the middle three measurements were taken into account. The average difference between the two measuring techniques was below $5 \%$. A detailed wear-rate calculation procedure can be found in [25].

The wear rates of the lower plastic (rotating) discs were determined with the use of a stylus profilometer (Hommelwerke T8000GmbH, Germany). The surface of the wear scar was measured at four representative points, as denoted by the red lines on the wear scar in Figure $1 \mathrm{a}$, and the volume of the worn material was calculated with equation (1):

$w=\frac{\Delta V}{P \cdot s}($ eq. 1$)$ 
This peer reviewed manuscript has been accepted for publications to the Lubrication Science. Cite this article as: A. Pogačnik, A. Kupec, M. Kalin, Tribological properties of polyamide (PA6) in self mated contacts and against steel as a stationary and moving body, Wear, Volumes 378-379, 2017, Pages 17-26, ISSN 0043-1648, https://doi.org/10.1016/j.wear.2017.01.118.

where $\Delta V$ is the volume of the worn material, $P$ is the normal load and $s$ is the total sliding distance.

The worn surfaces were examined using a scanning electron microscope or SEM (JEOL JSMT330A, Japan) at an accelerating voltage of $20 \mathrm{kV}$ and an Inco Energy data-processing unit (Oxford Instruments Analytical Ltd., UK). Prior to the examination, the pin specimens were sputter coated (SCD005, Bal-tec AG, Liechtenstein) with Au for $300 \mathrm{~s}$.

\section{Results}

\subsection{PA6 pin sliding against SS disc}

The evolution of the coefficient of friction with the sliding distance for the PA6/SS contact configuration under mild contact conditions of $0.4 \mathrm{~m} / \mathrm{s}$ and $6 \mathrm{~N}$ is shown in Figure 2 as a representative test, since similar behaviour was observed regardless of the conditions used. Initially, the coefficient of friction is 0.36 , after which it increases sharply to a value of around 0.44 in the first $500 \mathrm{~m}$. Afterwards, the coefficient of friction is very stable at the same value, meaning that a steady-state friction has been reached.

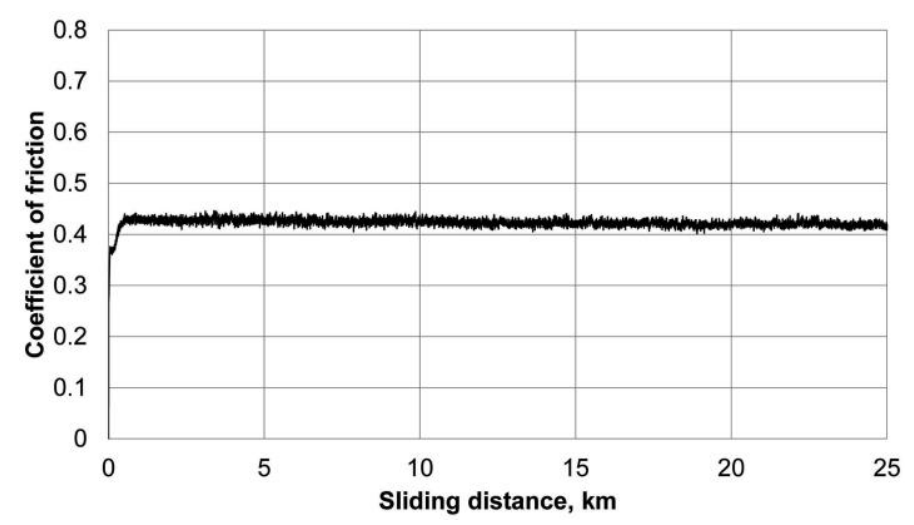

Figure 2: Evolution of the coefficient of friction with the sliding distance for the PA6/SS contact configuration at $0.4 \mathrm{~m} / \mathrm{s}$ and $6 \mathrm{~N}$.

The dependence of the coefficient of friction on the normal load and the sliding velocity for the PA6/SS combination is shown in Figure 3a. The values of the coefficient of friction are 
This peer reviewed manuscript has been accepted for publications to the Lubrication Science. Cite this article as: A. Pogačnik, A. Kupec, M. Kalin, Tribological properties of polyamide (PA6) in self mated contacts and against steel as a stationary and moving body, Wear, Volumes 378-379, 2017, Pages 17-26, ISSN 0043-1648, https://doi.org/10.1016/j.wear.2017.01.118.

between 0.40 and 0.45 , and vary insignificantly with the changes in the sliding speed and the applied normal load.

The wear rate of the PA6 pin with respect to the sliding speed and normal load is shown in Figure $3 \mathrm{~b}$. The wear rates were between $1.08 \times 10^{-5} \mathrm{~mm}^{3} / \mathrm{Nm}$ and $2.00 \times 10^{-5} \mathrm{~mm}^{3} / \mathrm{Nm}$. At low normal loads ( $4 \mathrm{~N}$ or $6 \mathrm{~N}$ ), the wear of the PA6 pin slightly decreased with an increasing sliding speed or remained constant, within the standard deviations of the repeated tests. In contrast, the wear rate increased with an increasing speed when a normal load of $8 \mathrm{~N}$ is applied. An increasing load causes an increase in the wear of the PA6 pin, with the exception of the slowest sliding speed $(0.4 \mathrm{~m} / \mathrm{s})$, where the trend is not very clear.

The surface temperature of the PA6 pin in contact with the SS disc at various sliding speeds and applied loads is shown in Figure 3c. For the conditions used, the temperatures in the contact were between $33{ }^{\circ} \mathrm{C}$ and $47^{\circ} \mathrm{C}$, and the temperature increased almost linearly with both an increased sliding speed and applied load. 
This peer reviewed manuscript has been accepted for publications to the Lubrication Science.

Cite this article as: A. Pogačnik, A. Kupec, M. Kalin, Tribological properties of polyamide (PA6) in self mated contacts and against steel as a stationary and moving body, Wear, Volumes 378-379, 2017, Pages 17-26, ISSN 0043-1648, https://doi.org/10.1016/j.wear.2017.01.118.
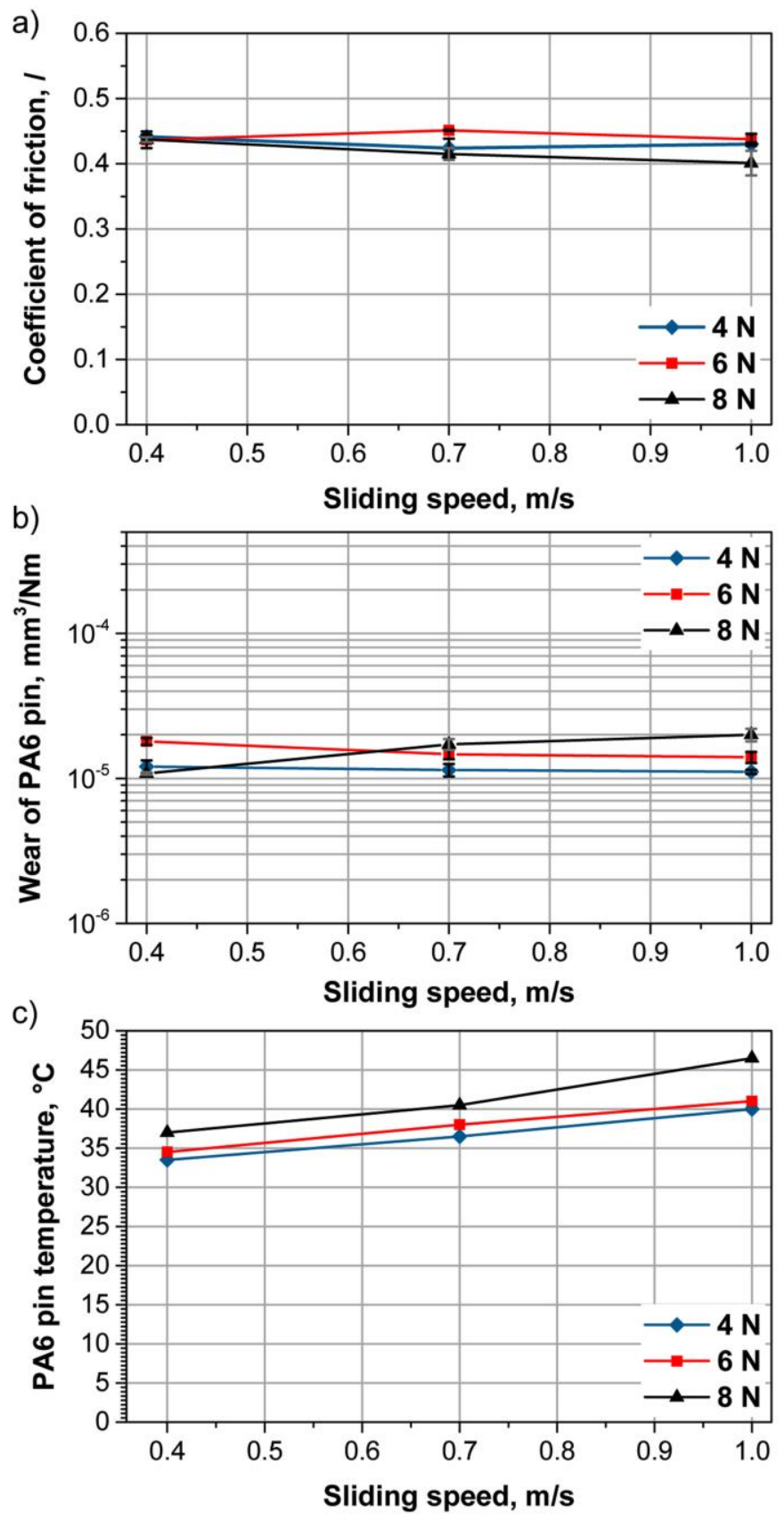

Figure 3: a) Coefficient of friction, b) wear of the stationary PA6 pin and c) temperature of the PA6 pin for the PA6/SS combination.

After sliding under different contact conditions, the surfaces of the PA6 pins and SS discs were observed with the SEM in order to gain an insight into the wear mechanisms that take place. 
This peer reviewed manuscript has been accepted for publications to the Lubrication Science. Cite this article as: A. Pogačnik, A. Kupec, M. Kalin, Tribological properties of polyamide (PA6) in self mated contacts and against steel as a stationary and moving body, Wear, Volumes 378-379, 2017, Pages 17-26, ISSN 0043-1648, https://doi.org/10.1016/j.wear.2017.01.118.

The SEM images of the PA6 pins after the tests under the mildest and harshest conditions are shown in Figure 4. An abraded surface with wear marks oriented in the direction of sliding can be seen on a PA6 pin after sliding at the mildest conditions $0.4 \mathrm{~m} / \mathrm{s}$ and $4 \mathrm{~N}$ (Figure $4 \mathrm{a}$ ). Similarly, sliding under the harshest contact conditions studied here $(1 \mathrm{~m} / \mathrm{s}$ and $8 \mathrm{~N})$ contributed to the formation of wear marks and, in addition, to smoother surface (see Figure 4b). Thus, the hard steel surface abraded soft polymer material, i.e. an abrasion wear mechanism is observed under the studied test conditions on PA6 pin surface. Note that the worn surfaces were also analysed after intermediate contact conditions, which revealed an abrasion wear mechanism in all cases (figures not shown here).

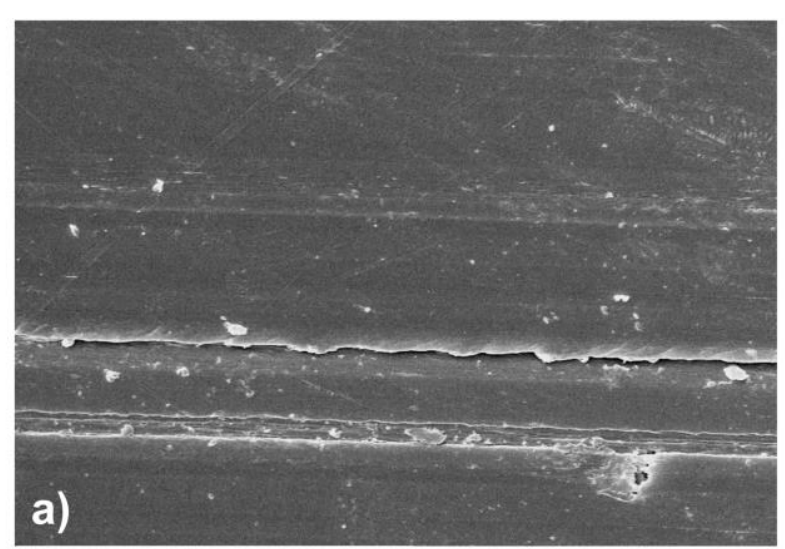

$60 \mu \mathrm{m}$

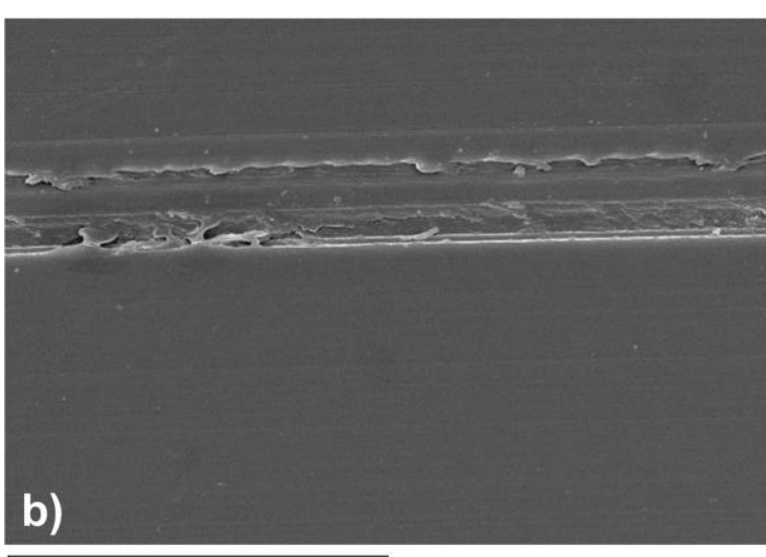

$60 \mu \mathrm{m}$

Figure 4: SEM images of PA6 pins surfaces after sliding against SS discs at a) $0.4 \mathrm{~m} / \mathrm{s}$ and $4 \mathrm{~N}$ and b) $1 \mathrm{~m} / \mathrm{s}$ and $8 \mathrm{~N}$.

Figure 5 shows a representative SEM image of the worn SS disc after sliding at $6 \mathrm{~N}$ and 0.4 $\mathrm{m} / \mathrm{s}$. Randomly oriented grinding marks and plastically deformed material on their edges, caused by sample preparation finishing can be observed. No transfer PA6 film formed on the steel surface. Note that the surfaces of the SS discs after the tribological tests with the PA6/SS combination at other contact conditions showed similar features. The observed absence of transfer film is in agreement with low contact temperatures of the PA6 pin during the measurement (see Figure 3c) as well with the observed very stable coefficient of friction (see Figure 3a). 
This peer reviewed manuscript has been accepted for publications to the Lubrication Science. Cite this article as: A. Pogačnik, A. Kupec, M. Kalin, Tribological properties of polyamide (PA6) in self mated contacts and against steel as a stationary and moving body, Wear, Volumes 378-379, 2017, Pages 17-26, ISSN 0043-1648, https://doi.org/10.1016/j.wear.2017.01.118.

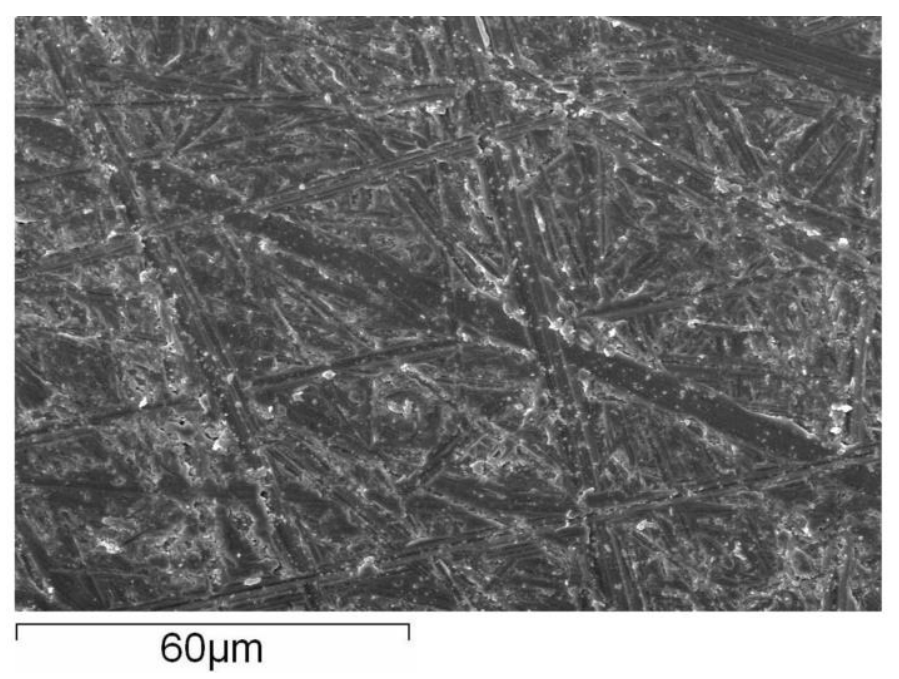

Figure 5: SEM image of SS disc after sliding against PA6 pin at $6 \mathrm{~N}$ and $0.4 \mathrm{~m} / \mathrm{s}$.

Thus, based on the SEM topographical analysis of worn surfaces the wear mechanism remained the same in the case of the PA6/SS combination in the studied broad range of testing conditions. Namely, the PA6 pin wore by abrasion and the SS disc did not show measurable wear.

\subsection{SS pin sliding against PA6 disc}

The evolution of the coefficient of friction with the sliding distance measured for the SS/PA6 contact combination under mild conditions of $0.7 \mathrm{~m} / \mathrm{s}$ and $4 \mathrm{~N}$ is shown in Figure 6 . Note that for all conditions, the evolution of the coefficient of friction with sliding distance was very similar. For this reason, all the curves are not shown here. Initially, the coefficient of friction is 0.22 . A sharp increase in the value over the first $500 \mathrm{~m}$ is followed by a more gradual increase and a slight decrease in the first $6 \mathrm{~km}$. After that, the average value is constant at a mostly steady state of 0.96 , but it exhibits slight instabilities that become more pronounced after approximately $12 \mathrm{~km}$. 
This peer reviewed manuscript has been accepted for publications to the Lubrication Science. Cite this article as: A. Pogačnik, A. Kupec, M. Kalin, Tribological properties of polyamide (PA6) in self mated contacts and against steel as a stationary and moving body, Wear, Volumes 378-379, 2017, Pages 17-26, ISSN 0043-1648, https://doi.org/10.1016/j.wear.2017.01.118.

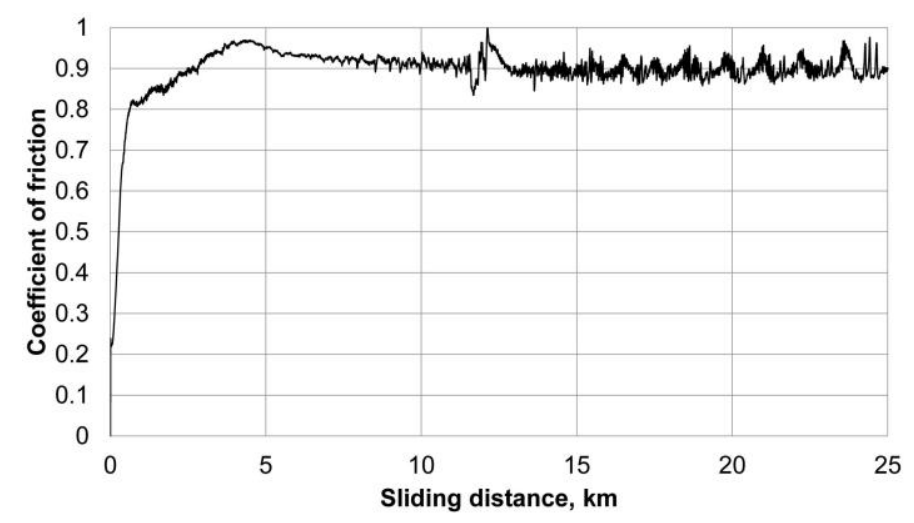

Figure 6: Evolution of the coefficient of friction with sliding distance for SS/PA6 at $0.7 \mathrm{~m} / \mathrm{s}$ and $4 \mathrm{~N}$.

Figure 7a shows the coefficient of friction for the SS/PA6 pin-on-disc combination under different contact conditions. Regardless of the normal load, the coefficient of friction is almost constant at speeds between $0.4 \mathrm{~m} / \mathrm{s}$ and $0.7 \mathrm{~m} / \mathrm{s}$, with the values ranging between 0.96 and 1.06. A further increase in the speed from $0.7 \mathrm{~m} / \mathrm{s}$ to $1 \mathrm{~m} / \mathrm{s}$ resulted in decreased values for the coefficient of friction. A drop of less than $15 \%$ or $10 \%$ is observed when a normal load of $4 \mathrm{~N}$ or $6 \mathrm{~N}$ is applied, respectively. For the contact load of $8 \mathrm{~N}$, the coefficient of friction drops by about $25 \%$, to a value of 0.74 . The coefficient of friction increases with the decreasing normal load at $0.7 \mathrm{~m} / \mathrm{s}$, whereas at sliding speeds of $0.4 \mathrm{~m} / \mathrm{s}$ or $1 \mathrm{~m} / \mathrm{s}$, the trend is not straightforward.

The wear rates of the rotational PA6 disc for the different contact conditions are presented in Figure $7 \mathrm{~b}$. For the applied normal load of $4 \mathrm{~N}$, the wear rate increased from $5.55 \times 10^{-6}$ $\mathrm{mm}^{3} / \mathrm{Nm}$ to almost double that value of $1.18 \times 10^{-5} \mathrm{~mm}^{3} / \mathrm{N}$ as the sliding speed was raised from $0.4 \mathrm{~m} / \mathrm{s}$ to $1 \mathrm{~m} / \mathrm{s}$. At higher loads, i.e., $6 \mathrm{~N}$ and $8 \mathrm{~N}$, the increase in the nominal wear with the sliding speed was even more pronounced, it increased from $9.33 \times 10^{-6} \mathrm{~mm}^{3} / \mathrm{N}$ to $9.93 \times 10^{-5} \mathrm{~mm}^{3} / \mathrm{N}$ and from $3.75 \times 10^{-6} \mathrm{~mm}^{3} / \mathrm{N}$ to as much as $1.21 \times 10^{-4} \mathrm{~mm}^{3} / \mathrm{N}$, respectively. Note that compared to the applied load of $8 \mathrm{~N}$, a gradual increase in the wear at $6 \mathrm{~N}$ takes place at a faster sliding speed.

The measured surface temperature of the SS pin ranges between $67^{\circ} \mathrm{C}$ and $160^{\circ} \mathrm{C}$ (Figure $7 \mathrm{c}$ ) and it increases almost linearly with the increasing sliding speed and normal load. The difference in the temperatures is substantial and could therefore cause changes in the mechanical and thermal properties of the plastic materials in the contact. 
This peer reviewed manuscript has been accepted for publications to the Lubrication Science. Cite this article as: A. Pogačnik, A. Kupec, M. Kalin, Tribological properties of polyamide (PA6) in self mated contacts and against steel as a stationary and moving body, Wear, Volumes 378-379, 2017, Pages 17-26, ISSN 0043-1648, https://doi.org/10.1016/j.wear.2017.01.118.

After the tribological test, the worn surfaces were examined with the SEM to analyse the wear mechanisms.

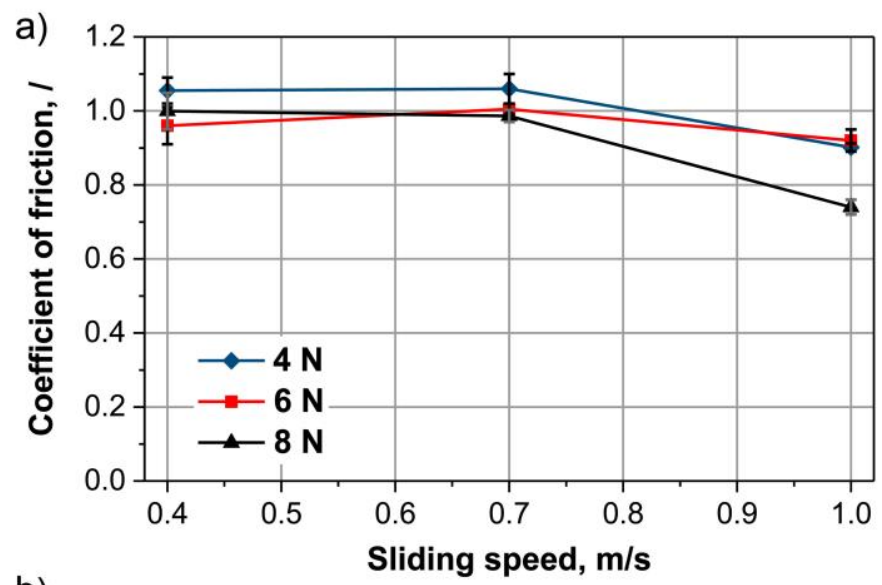

b)
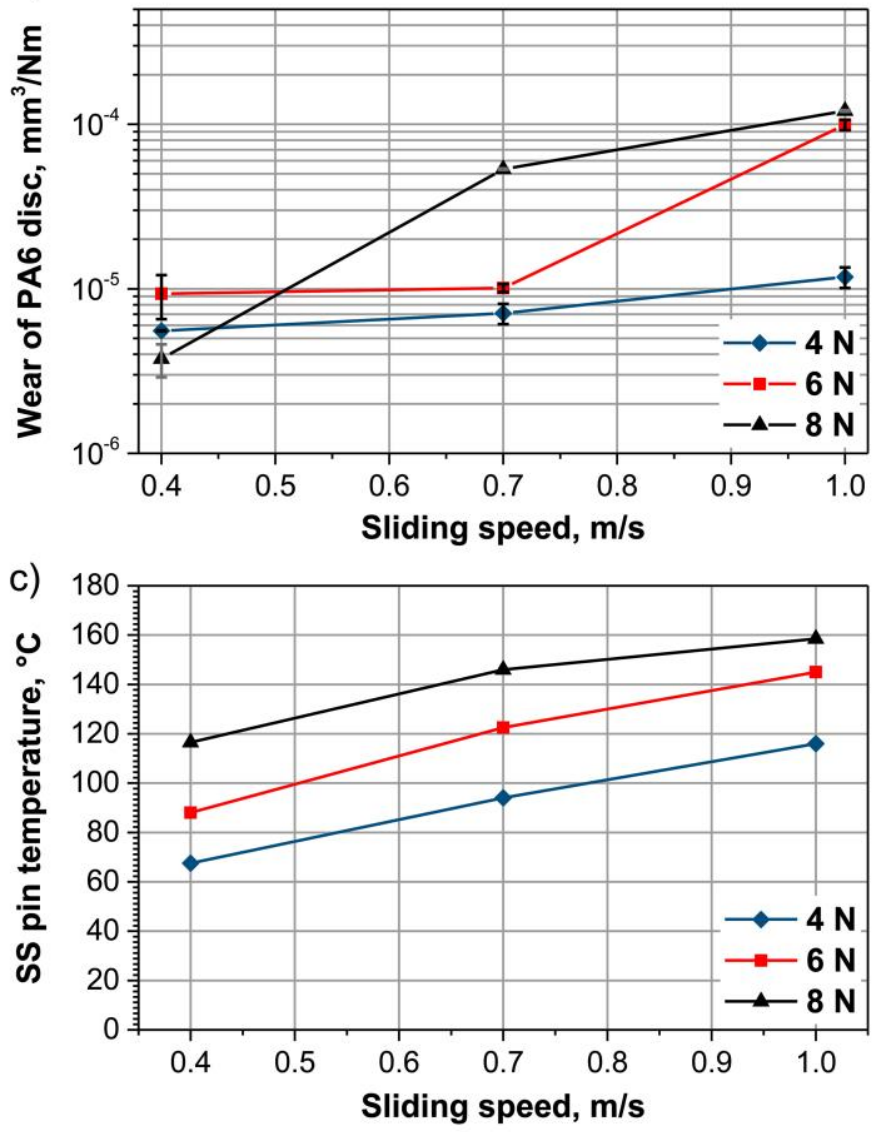

Figure 7: a) Coefficient of friction, b) wear of rotating PA6 disc and c) temperature of the stationary SS pin for the SS/PA6 combination. 
This peer reviewed manuscript has been accepted for publications to the Lubrication Science. Cite this article as: A. Pogačnik, A. Kupec, M. Kalin, Tribological properties of polyamide (PA6) in self mated contacts and against steel as a stationary and moving body, Wear, Volumes 378-379, 2017, Pages 17-26, ISSN 0043-1648, https://doi.org/10.1016/j.wear.2017.01.118.

SEM images of a stationary steel (SS) pin are shown in Figure 8. Under mild conditions $(0.4 \mathrm{~m} / \mathrm{s}$ and $4 \mathrm{~N})$, a PA6 transfer film forms on the steel (SS) surface, together with some additionally adhered wear particles that can be observed in Figure 8a. Similarly, after sliding under much harsher conditions, i.e., at $1 \mathrm{~m} / \mathrm{s}$ and $8 \mathrm{~N}$, the transfer film is formed (Figure $8 \mathrm{~b}$ ). However, this film is more comprehensive and smeared in the direction of the sliding, indicating that a substantial plastic deformation of the transfer-film material occurred. No additional wear particles can be seen on the surface of the transfer film under these test conditions.

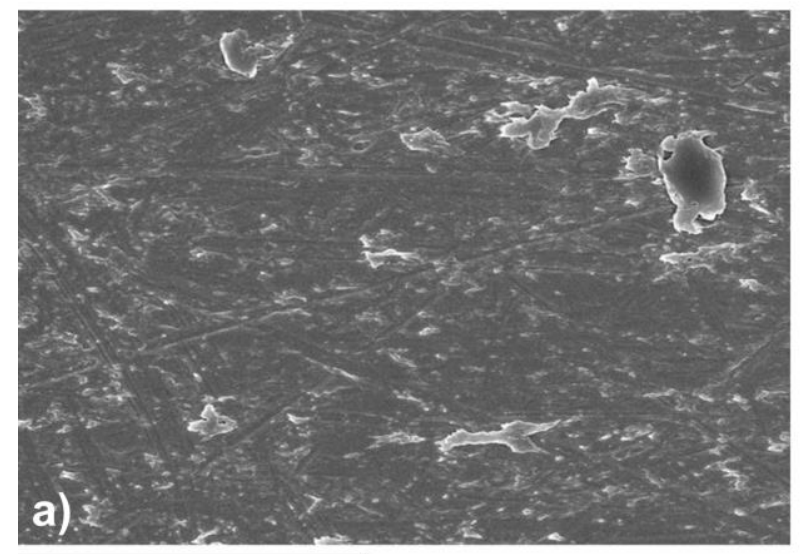

$60 \mu \mathrm{m}$

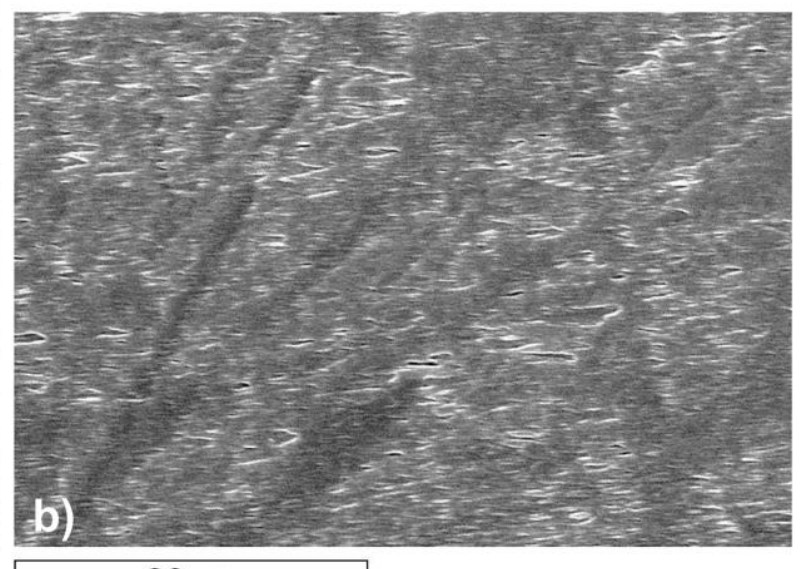

$60 \mu \mathrm{m}$

Figure 8: Sliding surface of stationary steel pin for the configuration SS/PA6 at a) $0.4 \mathrm{~m} / \mathrm{s}$ and $4 \mathrm{~N}$ and b) $1 \mathrm{~m} / \mathrm{s}$ and $8 \mathrm{~N}$ contact conditions.

The worn surfaces of the SS pin counter body, i.e., the PA6 disc are presented in Figure 9. Under mild conditions $(0.4 \mathrm{~m} / \mathrm{s}$ and $4 \mathrm{~N})$ some worn material adhered to the PA6 disc surface, as can be observed in Figure 9a. In addition, wear marks can be seen on the surface, indicating an abrasion wear mechanism. As is clear from Figure 8a, the transfer film on the steel pin is not uniformly formed over the whole surface; therefore, it is possible that the uncovered parts of the SS pin contributed to the abrasion mechanism observed on the surface of the PA6 disc. Moreover, the deformed transfer film itself and its asperities most probably caused the abrasion to the PA6 disc as well, which is typical for transfer films. The worn surface of the PA6 disc after sliding at $0.7 \mathrm{~m} / \mathrm{s}$ and $8 \mathrm{~N}$, shown in Figure $9 \mathrm{~b}$ reveals adhesion, 
This peer reviewed manuscript has been accepted for publications to the Lubrication Science. Cite this article as: A. Pogačnik, A. Kupec, M. Kalin, Tribological properties of polyamide (PA6) in self mated contacts and against steel as a stationary and moving body, Wear, Volumes 378-379, 2017, Pages 17-26, ISSN 0043-1648, https://doi.org/10.1016/j.wear.2017.01.118.

melting and plastic deformation. Small particles, adhered to the surface, oriented wear marks and some minor plastic deformation can be observed on the surface of PA6 disc after sliding at $1 \mathrm{~m} / \mathrm{s}$ and $8 \mathrm{~N}$ (Figure 9c).
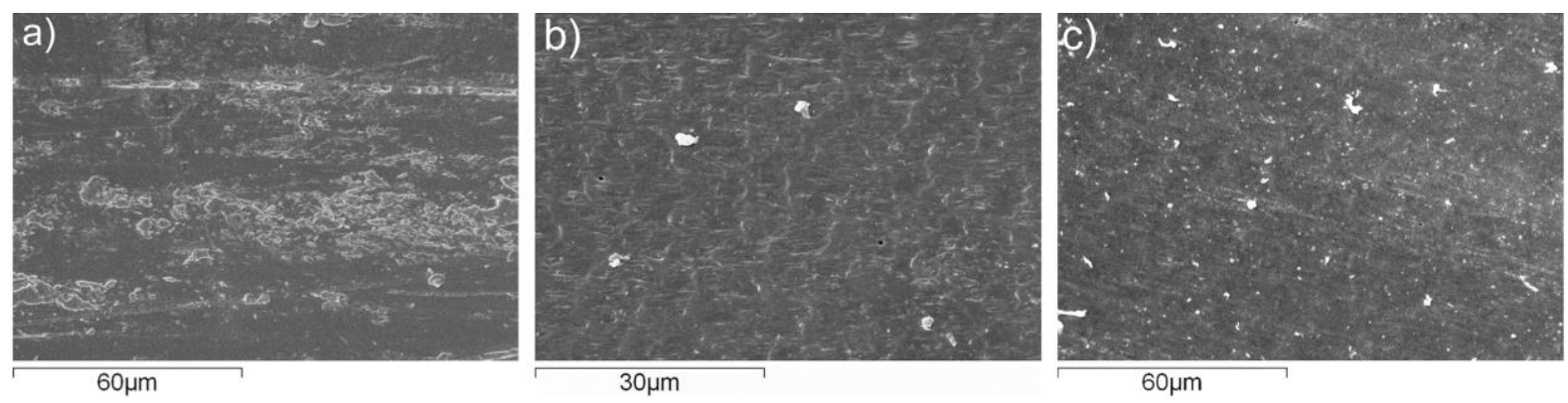

Figure 9: Sliding surface of PA6 disc for the combination SS/PA6 at a) $0.4 \mathrm{~m} / \mathrm{s}$ and $4 \mathrm{~N}, \mathrm{~b}$ )

$0.7 \mathrm{~m} / \mathrm{s}$ and $8 \mathrm{~N}$ (note higher magnification for improved clearness) and c) $1 \mathrm{~m} / \mathrm{s}$ and $8 \mathrm{~N}$.

The wear maps for SS/PA6 in Figure 10 summarize the wear mechanisms observed on the worn surfaces of the SS pins (Figure 10a) and the PA6 discs (Figure 10b) after sliding under different contact conditions.

Regardless of the testing conditions, a PA6 transfer film was formed on the SS pin surfaces (Figure 10a). Two different phenomena occurred on the formed PA6 transfer film. Namely, at lower sliding speeds and normal loads, plastic deformation of the transfer-film surface took place. Additionally, more severe contact conditions gave rise to melting of the transfer film.

Under low and intermediate normal loads, the PA6 disc surface is abraded with some wear particles being adhered to the surface (Figure 10b). At high normal loads, the mechanism changes to adhesion with plastic deformations of the surface and also with local melting of the surface. It is interesting to note that this change due to temperature increase at $8 \mathrm{~N}$ and low velocity results in even lower wear compared to lower studied loads ( $4 \mathrm{~N}$ or $6 \mathrm{~N}$ ), Figure $7 \mathrm{~b}$. However, at $1 \mathrm{~m} / \mathrm{s}$ and $8 \mathrm{~N}$, adhesion occurs, but in this case only with plastic deformations of the surface. No surface melting is noted, which can be related to the low coefficient of friction under these test conditions (Figure 7a). 
This peer reviewed manuscript has been accepted for publications to the Lubrication Science. Cite this article as: A. Pogačnik, A. Kupec, M. Kalin, Tribological properties of polyamide (PA6) in self mated contacts and against steel as a stationary and moving body, Wear, Volumes 378-379, 2017, Pages 17-26, ISSN 0043-1648, https://doi.org/10.1016/j.wear.2017.01.118.
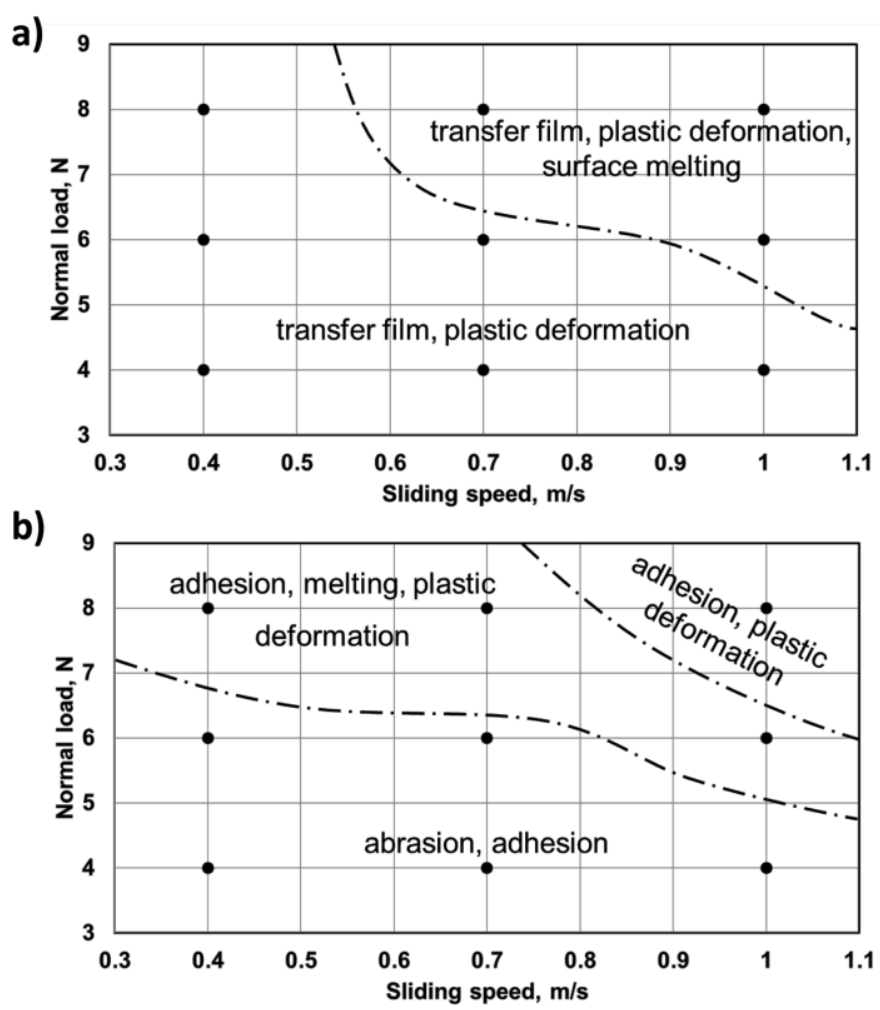

Figure 10: Wear maps of the SS/PA6 contacts describing the wear mechanisms of a) the SS pin and b) the PA6 disc after sliding under different contact conditions.

\subsection{PA6/PA6 self-mated contact}

The evolution of the coefficient of friction with the sliding distance for the PA6/PA6 contact configuration sliding at $0.7 \mathrm{~m} / \mathrm{s}$ and $4 \mathrm{~N}$ is shown in Figure 11, and similar features were also observed under different sliding conditions. Initially, the coefficient of friction is around 0.2 , and based on gradual deviations in the first $15 \mathrm{~km}$ we can describe it as the running-in period. At longer distances, the average coefficient of friction value is around 1.09, but it exhibits sharp peaks and instabilities throughout the whole $50 \mathrm{~km}$ of sliding distance. It should be noted that the running-in phase, before reaching the steady-state coefficient of friction, is much longer than in both the other two contacts, including the steel samples. 
This peer reviewed manuscript has been accepted for publications to the Lubrication Science. Cite this article as: A. Pogačnik, A. Kupec, M. Kalin, Tribological properties of polyamide (PA6) in self mated contacts and against steel as a stationary and moving body, Wear, Volumes 378-379, 2017, Pages 17-26, ISSN 0043-1648, https://doi.org/10.1016/j.wear.2017.01.118.

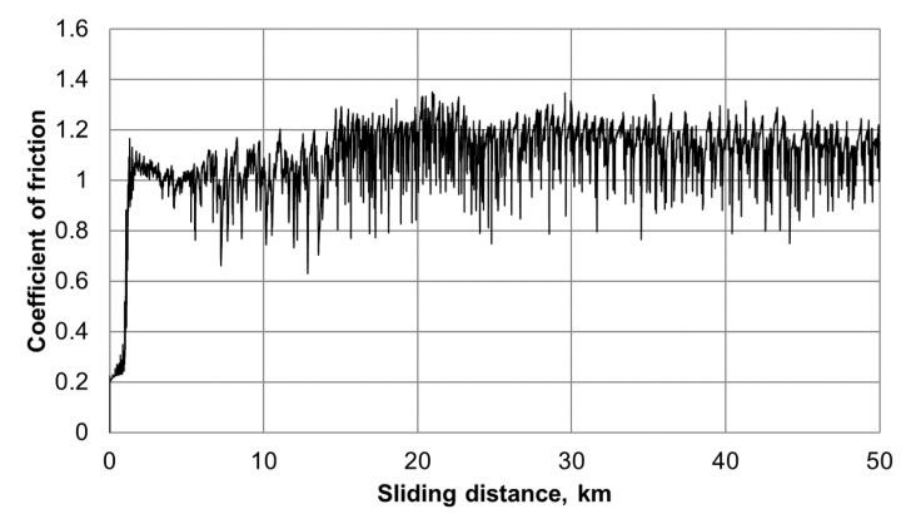

Figure 11: Evolution of the coefficient of friction with sliding distance for PA6/PA6 at $0.7 \mathrm{~m} / \mathrm{s}$ and $4 \mathrm{~N}$.

The coefficient of friction, wear and temperature for the PA6/PA6 contact configuration are shown in Figure 12. For sliding speeds of $1 \mathrm{~m} / \mathrm{s}$ in the case of the $4 \mathrm{~N}$ normal load and at 0.7 $\mathrm{m} / \mathrm{s}$ or more in the case of the $6 \mathrm{~N}$ load (or higher), severe vibrations took place during the measurements, resulting in a non-representative testing quantification and severe macro deformation of the stationary samples. Therefore, due to the poor tribological behaviour, the results are not included in Figure 12.

The coefficient of friction at $4 \mathrm{~N}$ and $0.4 \mathrm{~m} / \mathrm{s}$ is 0.92 , and it increases to 1.09 as the speed is increased to $0.7 \mathrm{~m} / \mathrm{s}$. By increasing the normal load, the coefficient of friction at $0.4 \mathrm{~m} / \mathrm{s}$ drops to 0.77 and 0.81 for the $6 \mathrm{~N}$ and $8 \mathrm{~N}$, respectively.

The wear rate of the stationary pin at $4 \mathrm{~N}$ and $0.4 \mathrm{~m} / \mathrm{s}$ is $1.7 \times 10^{-6} \mathrm{~mm}^{3} / \mathrm{Nm}$ (Figure $12 \mathrm{~b}$ ), which is lower than the $2.45 \times 10^{-6} \mathrm{~mm}^{3} / \mathrm{Nm}$ wear rate of the rotating disc (Figure 12c). For both the pin and disc, a slight drop in the wear rate is observed at higher loads, and a significant increase, i.e. to $1.95 \times 10^{-5} \mathrm{~mm}^{3} / \mathrm{Nm}$ for pin and to $4.73 \times 10^{-5} \mathrm{~mm}^{3} / \mathrm{Nm}$ for disc when the sliding speed was raised to $0.7 \mathrm{~m} / \mathrm{s}$ (at $4 \mathrm{~N}$ ).

Figure 12d shows that the PA6 pin temperature was increased with an increasing speed and load, and it varied between $75^{\circ} \mathrm{C}$ and $100{ }^{\circ} \mathrm{C}$ under the applied test conditions. 
This peer reviewed manuscript has been accepted for publications to the Lubrication Science.

Cite this article as: A. Pogačnik, A. Kupec, M. Kalin, Tribological properties of polyamide (PA6) in self mated contacts and against steel as a stationary and moving body, Wear, Volumes 378-379, 2017, Pages 17-26, ISSN 0043-1648, https://doi.org/10.1016/j.wear.2017.01.118.

a)

b)
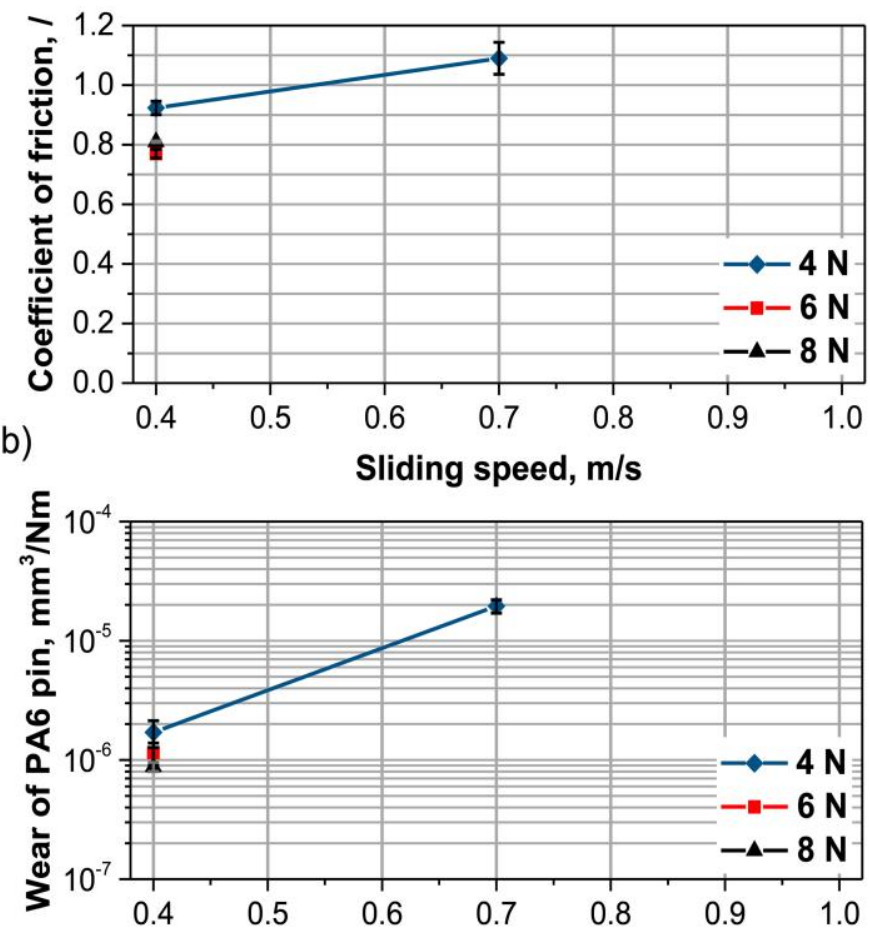

c)

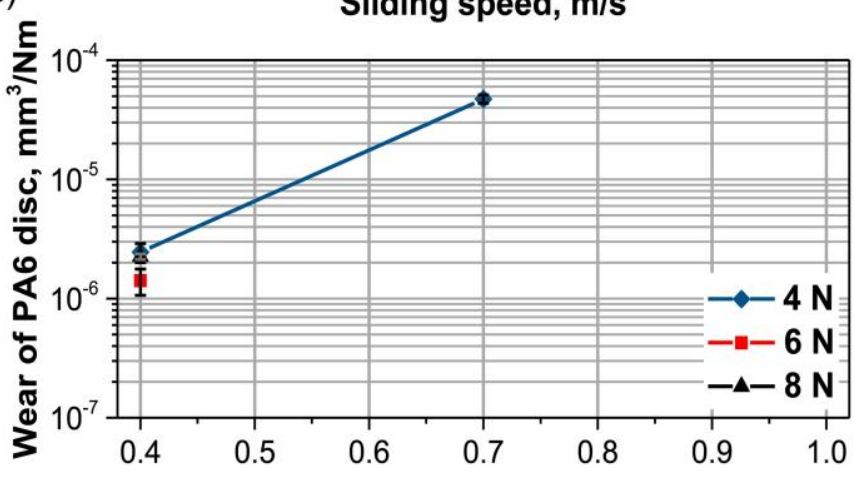

d)

Sliding speed, $\mathrm{m} / \mathrm{s}$

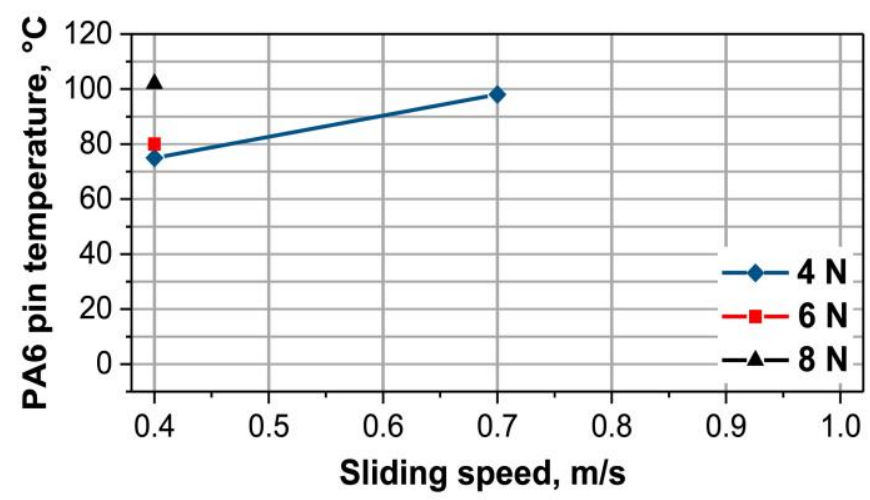

Figure 12: a) Coefficient of friction, b) wear of the stationary pin, c) wear of the rotating disc and d) temperature of the stationary pin for the PA6/PA6 contact configuration. Note that for 
This peer reviewed manuscript has been accepted for publications to the Lubrication Science. Cite this article as: A. Pogačnik, A. Kupec, M. Kalin, Tribological properties of polyamide (PA6) in self mated contacts and against steel as a stationary and moving body, Wear, Volumes 378-379, 2017, Pages 17-26, ISSN 0043-1648, https://doi.org/10.1016/j.wear.2017.01.118.

higher velocities and pressures $(\geq 1 \mathrm{~m} / \mathrm{s}$ at $4 \mathrm{~N}$ or $\geq 0.7 \mathrm{~m} / \mathrm{s}$ at $\geq 6 \mathrm{~N})$, a representative quantification could not be made.

Selected SEM images of the worn PA6 pin and PA6 disc surfaces are shown in Figure 13 and Figure 14, respectively. Regardless of the test conditions, the adhesion of material with plastic deformation in the direction of sliding and adhered wear particles can be observed on the worn surfaces. The amount of wear particles seems to be larger on the pin, and even more on disc, exposed to slower sliding speeds and loads (Figure 13a and Figure 14a), while plastic deformation is more pronounced after sliding under the harshest conditions (Figure 13b and Figure 14b). In addition, the sliding surfaces of the pins after both, and of disc after the harshest test conditions, are slightly melted on some parts, as we would expect based on the high contact temperatures (Figure 12d).
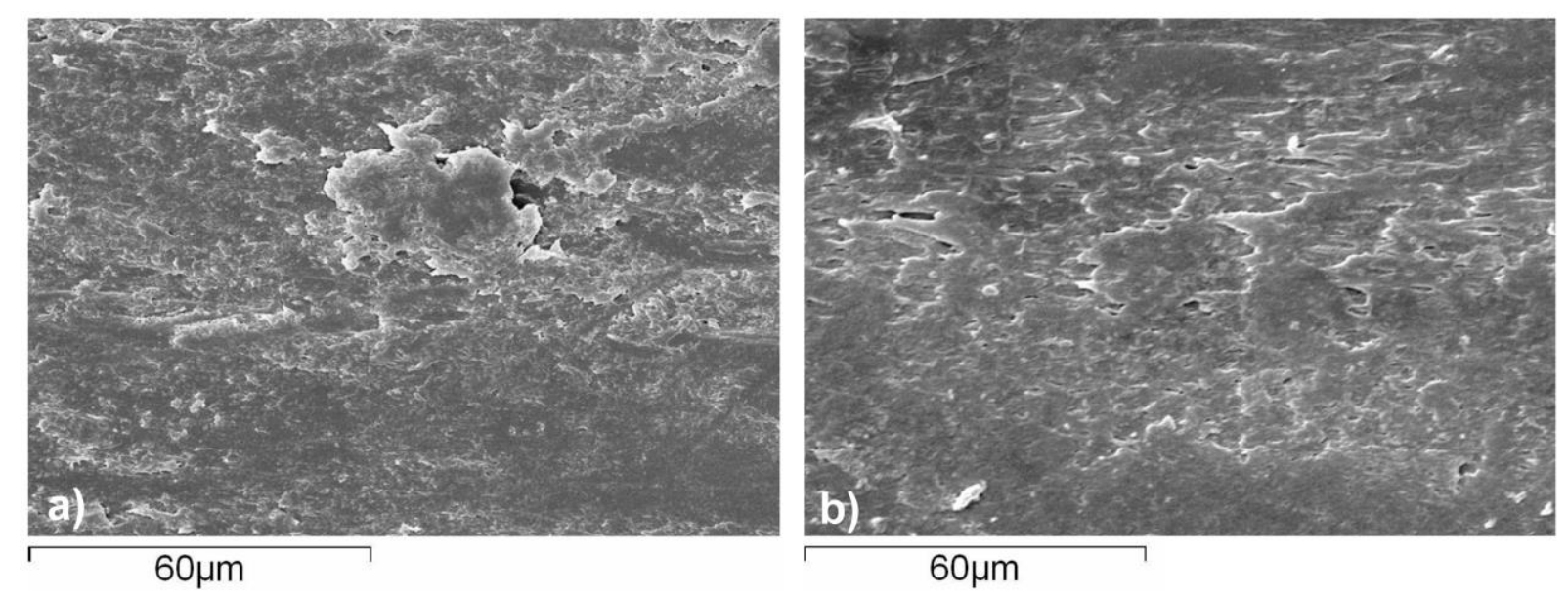

Figure 13: Sliding surface of PA6 pin for the combination PA6/PA6 at a) $0.4 \mathrm{~m} / \mathrm{s}$ and $4 \mathrm{~N}$ and b) $0.7 \mathrm{~m} / \mathrm{s}$ and $4 \mathrm{~N}$. 
This peer reviewed manuscript has been accepted for publications to the Lubrication Science. Cite this article as: A. Pogačnik, A. Kupec, M. Kalin, Tribological properties of polyamide (PA6) in self mated contacts and against steel as a stationary and moving body, Wear, Volumes 378-379, 2017, Pages 17-26, ISSN 0043-1648, https://doi.org/10.1016/j.wear.2017.01.118.

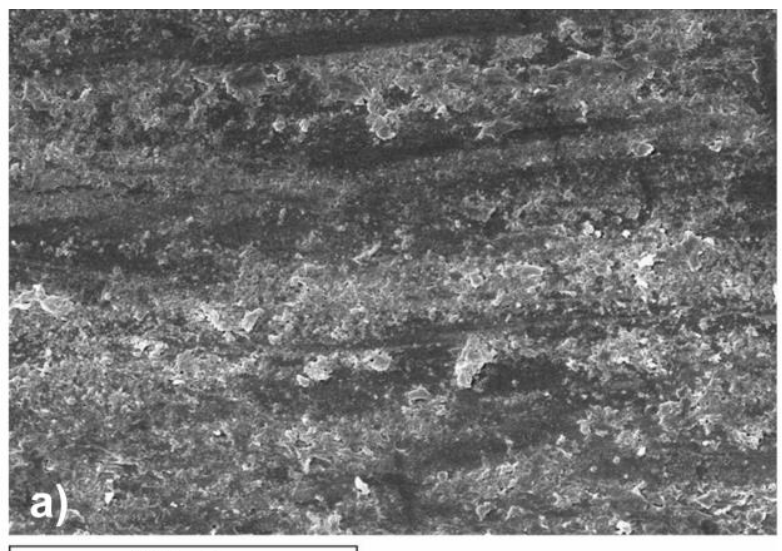

$60 \mu \mathrm{m}$

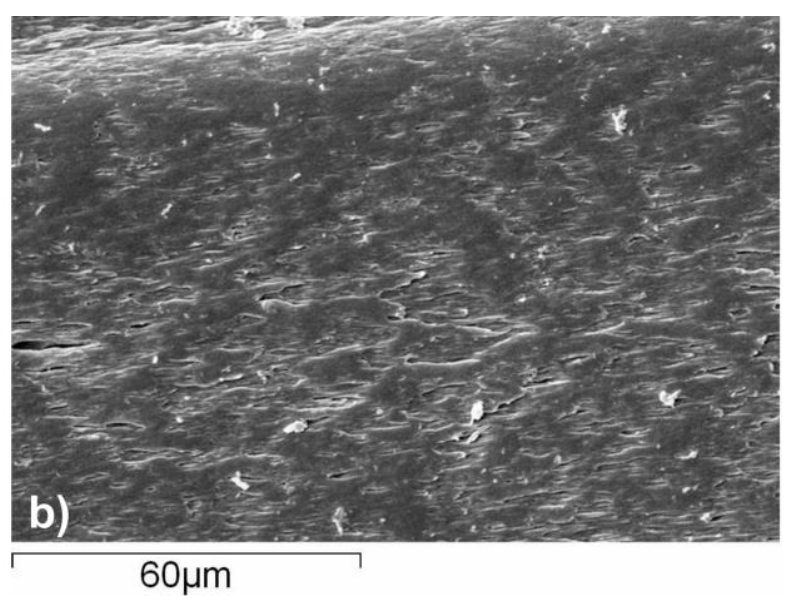

$60 \mu \mathrm{m}$

Figure 14: Sliding surface of rotating disc (PA6) for the combination PA6/PA6 at a) $0.4 \mathrm{~m} / \mathrm{s}$ and $4 \mathrm{~N}$ and b) $0.7 \mathrm{~m} / \mathrm{s}$ and $4 \mathrm{~N}$.

The PA6/PA6 wear maps in Figure 15 summarize the wear mechanisms found on the worn surfaces of the PA6 material after sliding in a self-mated contact under different sliding conditions. The main wear mechanisms observed on the worn surfaces of the pin are the adhesion of material with plastic deformation and surface melting in some places. Similar wear mechanisms were also observed on the worn disc surfaces, with the exception of the melting, which only took place under more severe sliding conditions (at/above $0.4 \mathrm{~m} / \mathrm{s}$ and 8 $\mathrm{N})$. 
This peer reviewed manuscript has been accepted for publications to the Lubrication Science. Cite this article as: A. Pogačnik, A. Kupec, M. Kalin, Tribological properties of polyamide (PA6) in self mated contacts and against steel as a stationary and moving body, Wear, Volumes 378-379, 2017, Pages 17-26, ISSN 0043-1648, https://doi.org/10.1016/j.wear.2017.01.118.

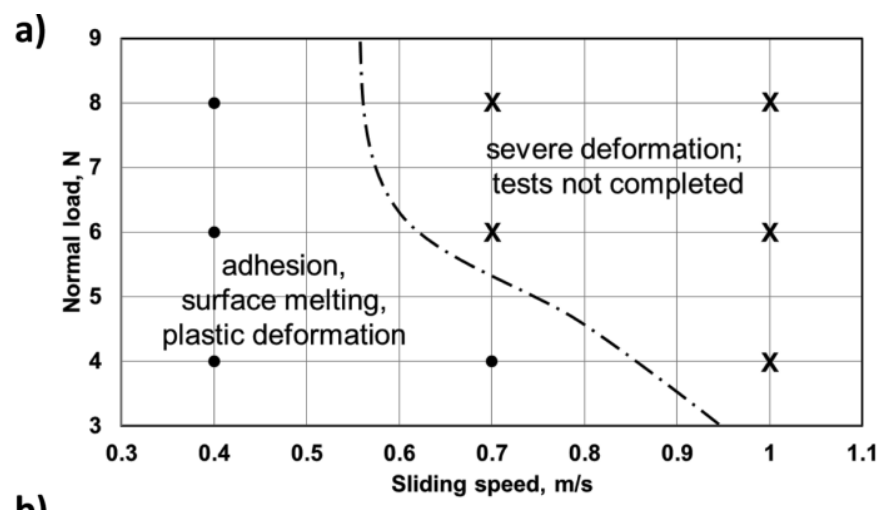

b)

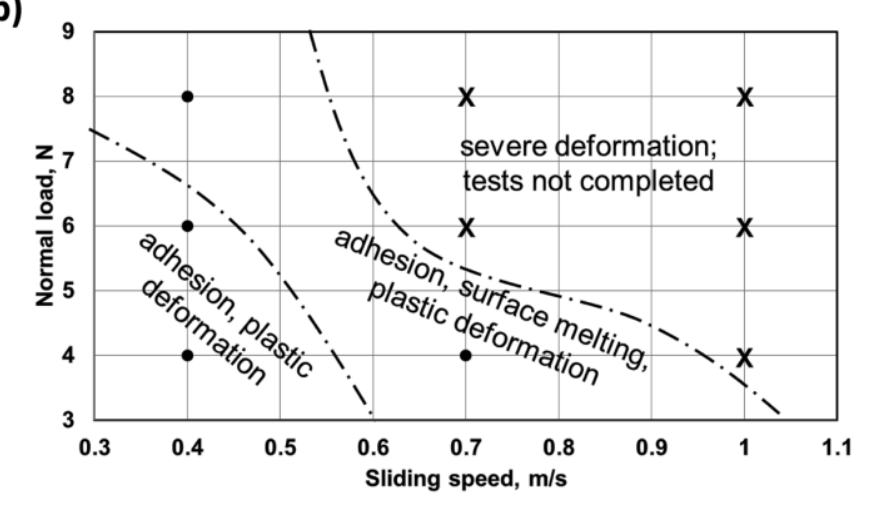

Figure 15: Wear maps of the PA6/PA6 contacts describing the wear mechanisms of a) the PA6 pin and b) the PA6 disc after sliding in a self-mated contact.

\section{Discussion}

For ease of comparison, the span in the coefficient-of-friction values, the wear rates on the pins and on the discs and the contact temperatures for the different contact configurations are summarized in Figure 16. It should be noted that all the tribological tests in this study were made for sufficiently long sliding distances to ensure fully steady-state conditions, which is often neglected or overlooked in the literature reports.

Depending on the material-pair configuration, the values as well as the deviations of the measured tribological properties in the studied pressure-velocity $(P V)$ range from 1.6 to 8 show a huge influence of the material-pair configuration. Below, the differences are discussed separately for the individual contact configurations. 
This peer reviewed manuscript has been accepted for publications to the Lubrication Science. Cite this article as: A. Pogačnik, A. Kupec, M. Kalin, Tribological properties of polyamide (PA6) in self mated contacts and against steel as a stationary and moving body, Wear, Volumes 378-379, 2017, Pages 17-26, ISSN 0043-1648, https://doi.org/10.1016/j.wear.2017.01.118.

a)

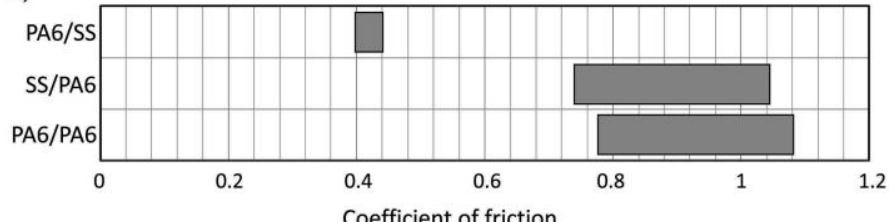

b)

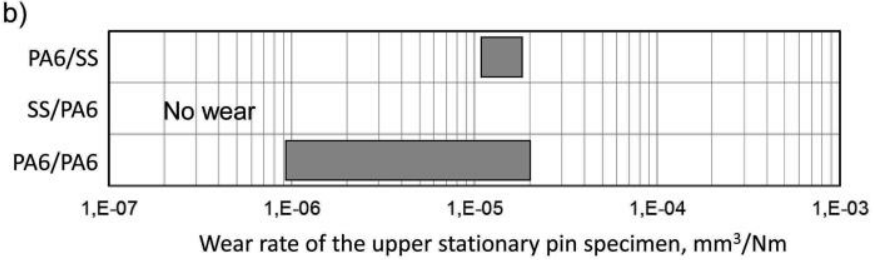

c)

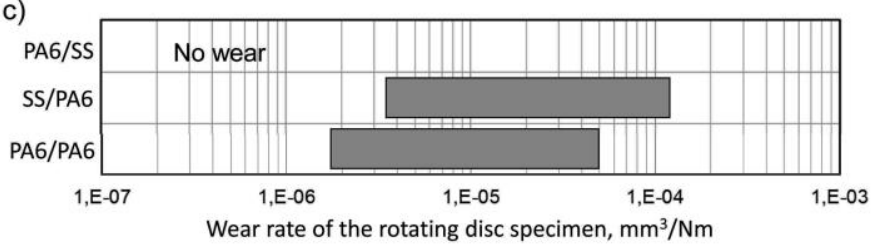

d)

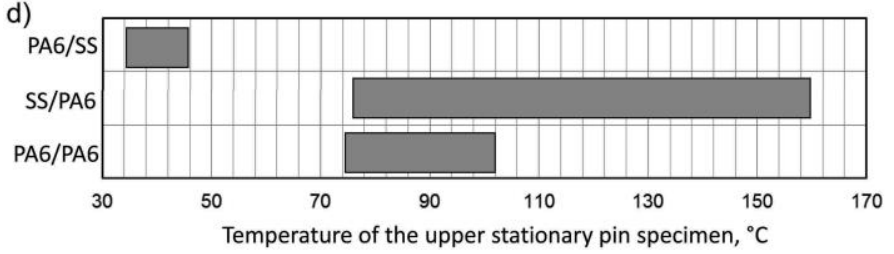

Figure 16: A comparison of a) the coefficients of friction, b) the pin wear rates, c) the disc wear rates and d) the contact temperatures for the different contact configurations, obtained for the full range of contact conditions in this study, corresponding to a $P V$ value from 1.6 to 8.0 .

\subsection{PA6/SS combination}

Compared to the vast span of the test conditions (the $P V$ value increased from 1.6 to 8 , Figure 16), the pin-on-disc test with the PA6/SS contact configuration exhibited a very stable coefficient of friction and wear rate. Furthermore, despite the much longer sliding distances, the tribological properties are comparable with the values for a PA6 pin sliding against a SS disc reported in the literature $[9,13,14]$.

Regardless of the changes in speed and load during the test, the topographical analysis revealed abrasion as the main wear mechanism observed on the PA6 pin, without the formation of a transfer film on the SS disc (Figure 5). Therefore, very stable friction and wear-rate values (see Figure 16) could be connected to the observed absence of change in the wear mechanism, as revealed by the topographical analysis of the worn surfaces, as well as 
This peer reviewed manuscript has been accepted for publications to the Lubrication Science. Cite this article as: A. Pogačnik, A. Kupec, M. Kalin, Tribological properties of polyamide (PA6) in self mated contacts and against steel as a stationary and moving body, Wear, Volumes 378-379, 2017, Pages 17-26, ISSN 0043-1648, https://doi.org/10.1016/j.wear.2017.01.118.

implied by the extremely small deviations in the friction with the sliding distance (Figure 2). The main reason for the good tribological properties is the low contact temperature, with a maximum temperature of $47{ }^{\circ} \mathrm{C}$ (Figure 3c). Although the fact that the local temperatures on the surface asperities at the real contact area [27] are higher than the measured bulk temperature $\left(47^{\circ} \mathrm{C}\right.$, Figure $\left.3 \mathrm{c}\right)$, it is clear that they are still below the allowable continuoususe temperature for the PA6, which was reported to be $80{ }^{\circ} \mathrm{C}[10]$ or $150{ }^{\circ} \mathrm{C}$ [1], since we could not find any traces of melting for the PA6 pin material. The abrasion wear mechanism also agrees with this.

We could thus connect the observed low surface (contact) temperatures to the presence of a moving steel disc in the tribological contact, having a much higher thermal conductivity than the polymers (Table 1). Consequently, the bulk material in the steel disc acts as a heat sink, which effectively draws the heat out of the contact and therefore enables an efficient cooling down of the steel (SS) surface before re-entering the contact with the PA6 pin.

\subsection{SS/PA6 combination}

The change in the contact configuration of the pin-on-disc test from PA6/SS to SS/PA6 contributed to a two-fold increase in the friction (Figure 7a) and, in contrast to the PA6/SS contact, to major changes in the contact temperatures from $70{ }^{\circ} \mathrm{C}$ to $160{ }^{\circ} \mathrm{C}$ (Figure $7 \mathrm{c}$ ) in the range of the test conditions used. Therefore, the acceptable, highest, short-term service temperatures of $180-200{ }^{\circ} \mathrm{C}[10]$ and continuous-use temperatures from $80{ }^{\circ} \mathrm{C}$ to $150{ }^{\circ} \mathrm{C}[1$, 10] that were reported for the PA6 were obviously exceeded, at least at the asperity level (Figure $7 \mathrm{a}$ and b, Figure 16).

The observed increase in the coefficient-of-friction values (Figure 16) in the SS/PA6 contact, as compared to the opposite PA6/SS contact, could be related to the changes in the prevailing wear mechanism due to the high temperatures in the contact. Namely, in contrast to the prevailing abrasion mechanism in the PA6/SS contact, in the case of the SS/PA6 contact, the adhesion was dominant and contributed to the formation of a PA6 transfer film on the SS pin (Figure 10a). Accordingly, the contact material pair in fact changed from a SS/PA6 to a PA6/PA6 contact and so the adhesion of the same contacting materials contributed to an increased friction. Note that the coefficient of friction values and wear rate in the case of 
This peer reviewed manuscript has been accepted for publications to the Lubrication Science. Cite this article as: A. Pogačnik, A. Kupec, M. Kalin, Tribological properties of polyamide (PA6) in self mated contacts and against steel as a stationary and moving body, Wear, Volumes 378-379, 2017, Pages 17-26, ISSN 0043-1648, https://doi.org/10.1016/j.wear.2017.01.118.

SS/PA6 material configuration are different as compared to PA6/SS configuration and comparable to the values measured in the PA6/PA6 material combination (Figure 16). Similarly, coefficient of friction between two cylindrical rings increased for up to three times when material combination was changed from PA6/steel to PA6/PA6 material combination [6].

Furthermore, as compared to the wear rate of the PA6/SS contact, a huge increase in the wear rate took place in the case of the SS/PA6 contact under harsher contact conditions, where the measured contact temperature was close to, or exceeded, $140{ }^{\circ} \mathrm{C}$. Clear surface melting was observed on the PA6 disc as well as on the transfer film formed on the steel pin's surface (see Figure 10). Interestingly, the observed changes in the wear mechanism (melting) and the increased wear rate are accompanied by a reduced coefficient of friction. This can be explained by the more viscous behaviour of the melted material in the tribological contact, where the movement of the molecules is facilitated, compared to the non-melted state. However, such behaviour goes hand in hand with a pronounced removal of material, reflected in an undesirable increase in the wear rate (Figure $7 b)$ [1].

The reason for the high temperatures lies in the fact that the rotating polymer disc is not able to cool down during one rotation, due to its poor thermal conductivity, while convection contributes very little to decreasing the surface temperature. The steel pin, however, is always in the contact and cannot cool, as well as having too small surface area to effectively sink all the heat that remains high at the interface. Furthermore, a transfer film was formed on the surface of the stationary steel (SS) pin, which additionally decreases its thermal conductivity due to the polymer transfer film's thermal barrier. This further contributes to the evolution of high contact temperatures.

As observed in Figure 16, this contact has the widest span of temperatures and reaches the highest values in this study. The same is also true for any polymer sample's wear, and quite correct for the friction as well. While PA6/SS is by far the best contact in this study, the SS/PA6 is a very poorly performing contact, and in some aspects it is the worst. This confirms the strong and inevitable importance of the contact design when combining polymers in tribological contacts. 
This peer reviewed manuscript has been accepted for publications to the Lubrication Science. Cite this article as: A. Pogačnik, A. Kupec, M. Kalin, Tribological properties of polyamide (PA6) in self mated contacts and against steel as a stationary and moving body, Wear, Volumes 378-379, 2017, Pages 17-26, ISSN 0043-1648, https://doi.org/10.1016/j.wear.2017.01.118.

\subsection{PA6/PA6 combination}

Among the studied contact configurations, PA6 in a self-mated contact exhibited the worst tribological properties. Besides a gradual deviation of the coefficient of friction with the sliding distance because of the dissipation of energies due to adhesive forces, the running-in period is 3 and 30 times longer as compared to the SS/PA6 and PA6/SS contact configurations, respectively (see Figures 2, 6 and 11). This is in agreement with the literature [25]. Furthermore, at or above $0.7 \mathrm{~m} / \mathrm{s}$ and $8 \mathrm{~N}$ macro deformations with catastrophic wear of the stationary pins occurred due to the high coefficient of friction (Figure 12a) and high contact temperatures (Figure 12d), which do not allow us to perform valid tests and obviously represent the limits for this contact configuration.

Nevertheless, for the mild sliding conditions $(0.4 \mathrm{~m} / \mathrm{s}$ and $4 \mathrm{~N})$, the wear rate of the PA6/PA6 contact configuration is even lower than for both contacts comprising steel (PA6/SS and SS/PA6), while the coefficient of friction is comparable to the value measured in the case of the SS/PA6 contacts (see Figure 16a). This clearly emphasises the critical importance of the contact temperature on the performance of polymer contacts. Namely, in the absence of high temperature and hard counterparts, like steel, that cause abrasion to the polymers with even limited surface imperfections, the self-mated polymer/polymer contacts perform quite well, with very little wear. However, an increase in the contact severity that will exceed the ability of the contacting bodies - particularly the moving one - to remove the frictional heat, will result in excessive temperature and, as a consequence, adhesion and contact failure. However, it should be pointed out that the above-mentioned limiting temperature is not a generic value since the contact temperature will depend on the contact geometry and the heat-removal ability, meaning that it is a contact-dependent parameter.

\section{Conclusions}

The influence of the material pairs configuration on tribological properties of polyamide 6 has been examined in this study using a pin on disc testing method. The wear rate and wear mechanisms of PA6 pin sliding against steel (PA6/SS) or PA6 disc (PA6/PA6), as well of steel pin sliding against PA6 disc (SS/PA6) have been analysed and related to the experimentally measured temperatures. The following conclusions were obtained: 
This peer reviewed manuscript has been accepted for publications to the Lubrication Science. Cite this article as: A. Pogačnik, A. Kupec, M. Kalin, Tribological properties of polyamide (PA6) in self mated contacts and against steel as a stationary and moving body, Wear, Volumes 378-379, 2017, Pages 17-26, ISSN 0043-1648, https://doi.org/10.1016/j.wear.2017.01.118.

- The limitations in terms of the normal load and speed applied to polymer-consisting contacts mainly depend on the temperature evolved in the contact and the ability of the selected contact configuration to remove the heat from the contact.

- The moving body is the one that defines how efficiently the heat can be removed from the contact, and so it should be made from a more thermally conductive material. This is essential for any contact design that includes polymer contact bodies.

- In the tribological contact of a PA6 pin/SS disc, the coefficient of friction, wear rate and wear mechanisms only exhibited negligible changes as the PV value increased from 1.6 to as much as 8 . Such behaviour has been connected with the low temperatures (below $47^{\circ} \mathrm{C}$ ) generated in the contact due to the steel disc acting as a heat sink and therefore providing sufficient cooling during the tribological test.

- The opposite material configuration, i.e., the SS pin/PA6 disc, was much less effective in removing the heat away from the contact. This contributed to high temperatures in the contact even under mild contact conditions and resulted in an up to two-fold increase in friction due to the adhesion at the polymer/polymer-transfer-film interface. Moreover, an increase in speed and/or load was also reflected in a huge increase in the wear rate.

- The self-mated PA6/PA6 contact exhibited the worst tribological properties due to an inability to remove the heat form the contact. This is already observed at intermediate loads/speeds, and much more under severe contact conditions, where some experiments could not even be performed in a valid manner ( $v=0.7 \mathrm{~m} / \mathrm{s}$ or higher).

- The running-in period is up to 3-times longer for the PA6/PA6 contacts than for the SS/PA6, and 30-times longer compared to the PA6/SS contacts.

- However, under very mild contact conditions the self-mated polymer contacts that maintain low contact temperatures are expected to have even lower wear than the steel-containing mixed polymer contacts due to the absence of steel abrasive wear, although the friction may not be so favourable and will depend on its adhesion component. 
This peer reviewed manuscript has been accepted for publications to the Lubrication Science. Cite this article as: A. Pogačnik, A. Kupec, M. Kalin, Tribological properties of polyamide (PA6) in self mated contacts and against steel as a stationary and moving body, Wear, Volumes 378-379, 2017, Pages 17-26, ISSN 0043-1648, https://doi.org/10.1016/j.wear.2017.01.118.

- Therefore, the design window for contact conditions in a tribological application depends on, and can be tailored by, a careful selection of not only the materials considered, but also on the contact-pair configuration of the materials in the tribological contact, as well as the contact conditions for which a certain material pair is used.

\section{Acknowledgements}

The authors would like to thank European Social Fund for its partial financial support.

\section{References}

[1] G.W. Stachowiak, A.W. Batchelor, 16 - Wear of Non-Metallic Materials, Engineering Tribology (Third Edition), Butterworth-Heinemann, Burlington, 2006, pp. 651-704.

[2] B.J. Briscoe, S.K. Sinha, CHAPTER 1 - Tribological applications of polymers and their composites: Past, present and future prospects, in: F. Klaus, K.S. Alois (Eds.) Tribology and Interface Engineering Series, Elsevier, 2008, pp. 1-14.

[3] A. Abdelbary, Wear of Polymers and Composites, Elsevier, Oxford, 2014.

[4] E. Letzelter, M. Guingand, J.-P.d. Vaujany, P. Schlosser, A new experimental approach for measuring thermal behaviour in the case of nylon 6/6 cylindrical gears, Polym. Test., 29 (2010) 10411051.

[5] G. Straffelini, S. Verlinski, P.C. Verma, G. Valota, S. Gialanella, Wear and Contact Temperature Evolution in Pin-on-Disc Tribotesting of Low-Metallic Friction Material Sliding Against Pearlitic Cast Iron, Tribol. Lett., 62 (2016) 1-11.

[6] M. Watanabe, M. Karasawa, K. Matsubara, The frictional properties of nylon, Wear, 12 (1968) 185-191.

[7] B.-B. Jia, T.-S. Li, X.-J. Liu, P.-H. Cong, Tribological behaviors of several polymer-polymer sliding combinations under dry friction and oil-lubricated conditions, Wear, 262 (2007) 1353-1359.

[8] N.K. Myshkin, S.S. Pesetskii, A.Y. Grigoriev, Polymer Tribology: Current State and Applications, Tribol. Ind., 37 (2015) 284-290.

[9] H. Czichos, Influence of adhesive and abrasive mechanisms on the tribological behaviour of thermoplastic polymers, Wear, 88 (1983) 27-43.

[10] D.K. Platt, Engineering and high performance plastics market report : a Rapra market report, Shrewsbury : Rapra Technology Ltd., [2003] @2003, 2003.

[11] E. Feyzullahoglu, Z. Saffak, The tribological behaviour of different engineering plastics under dry friction conditions, Mater. Design, 29 (2008) 205-211.

[12] J.W.M. Mens, A.W.J. de Gee, Friction and wear behaviour of 18 polymers in contact with steel in environments of air and water, Wear, 149 (1991) 255-268. 
This peer reviewed manuscript has been accepted for publications to the Lubrication Science. Cite this article as: A. Pogačnik, A. Kupec, M. Kalin, Tribological properties of polyamide (PA6) in self mated contacts and against steel as a stationary and moving body, Wear, Volumes 378-379, 2017, Pages 17-26, ISSN 0043-1648, https://doi.org/10.1016/j.wear.2017.01.118.

[13] H. Unal, A. Mimaroglu, Friction and wear behaviour of unfilled engineering thermoplastics, Mater. Design, 24 (2003) 183-187.

[14] H. Meng, G.X. Sui, G.Y. Xie, R. Yang, Friction and wear behavior of carbon nanotubes reinforced polyamide 6 composites under dry sliding and water lubricated condition, Compos. Sci. Technol., 69 (2009) 606-611.

[15] S.E. Franklin, Wear experiments with selected engineering polymers and polymer composites under dry reciprocating sliding conditions, Wear, 251 (2001) 1591-1598.

[16] S. Sathees Kumar, G. Kanagaraj, Investigation on Mechanical and Tribological Behaviors of PA6 and Graphite-Reinforced PA6 Polymer Composites, Arab. J. Sci. Eng., (2016) 1-11.

[17] S. Zhou, J. Huang, Q. Zhang, Mechanical and tribological properties of polyamide-based composites modified by thermoplastic polyurethane, J. Thermoplast. Compos., 27 (2014) 18-34.

[18] H. Unal, U. Sen, A. Mimaroglu, Dry sliding wear characteristics of some industrial polymers against steel counterface, Tribol. Int., 37 (2004) 727-732.

[19] X. Hu, Tribological behaviour of modified polyacetal against MC nylon without lubrication, Tribol. Lett., 5 (1998) 313-317.

[20] H. Unal, A. Mimaroglu, T. Arda, Friction and wear performance of some thermoplastic polymers and polymer composites against unsaturated polyester, Appl. Surf. Sci., 252 (2006) 8139-8146.

[21] H. Unal, F. Findik, Friction and wear behaviours of some industrial polyamides against different polymer counterparts under dry conditions, Ind. Lubr. Tribol., 60 (2008) 195-200.

[22] L. Lavielle, Polymer-polymer friction: Relation to adhesion, Wear, 151 (1991) 63-75.

[23] X.Q. Pei, K. Friedrich, Friction and Wear of Polymer Composites, Ref. Module Mat. Sci. Mat. Eng., Elsevier, 2016.

[24] Ultramid (PA) Product Range, BASF.

[25] A. Pogačnik, M. Kalin, Parameters influencing the running-in and long-term tribological behaviour of polyamide (PA) against polyacetal (POM) and steel, Wear, 290-291 (2012) 140-148.

[26] B.J. Briscoe, T.A. Stolarski, Wear of Polymers in the Pin-on-Disk Configuration, Polymer Wear and Its Control, American Chemical Society, 1985, pp. 303-313.

[27] A. Pogačnik, T. Požar, M. Kalin, J. Možina, A Homodyne Quadrature Laser Interferometer for Micro-Asperity Deformation Analysis, Sensors, 13 (2013) 703. 
This peer reviewed manuscript has been accepted for publications to the Lubrication Science.

Cite this article as: A. Pogačnik, A. Kupec, M. Kalin, Tribological properties of polyamide (PA6) in self mated contacts and against steel as a stationary and moving body, Wear, Volumes 378-379, 2017, Pages 17-26, ISSN 0043-1648, https://doi.org/10.1016/j.wear.2017.01.118. 